\title{
PELATIHAN STRATEGI PEMASARAN PRODUK VCO DAN TURUNANNYA DI IKM RUMAH IKHTIAR
}

\section{Training on Marketing Strategy for VCO Products and their derivates in IKM Rumah Ikhtiar}

\author{
Ingka Rizkyani Akolo'), Rosdiani Azis ${ }^{2)}$, Syahmidarni Al islamiyah ${ }^{3)}$, Moh. Fikri Pomalingo ${ }^{4)}$ Iqrima $^{1)}$ \\ Staddal $^{5}$ \\ ${ }^{1}$ Program Studi Pendidikan Agama Islam, IAIN Sultan Amai Gorontalo \\ ${ }^{2,3}$ Program Studi Teknologi Hasil Pertanian, Politeknik Gorontalo \\ ${ }^{4}$ Program Studi Teknik Mesin, Universitas Negeri Manado \\ ${ }^{5}$ Program Studi Mesin Pengolahan Pertanian, Politeknik Gorontalo \\ Email: inkarizkyani05@gmail.com ${ }^{1)}$
}

\begin{abstract}
ABSTRAK
IKM Rumah Ikhtiar merupakan IKM yang bergerak dalam bidang pengolahan kelapa khususnya pengolahan VCO dan produk turunannya. Besarnya potensi pemasaran VCO, permintaan arang, dan penggunaan etanol sebagai bahan pembuatan handsanitizer di masa pandemi menunjukkan bahwa produk olahan IKM ini cukup penting. Akan tetapi, saat ini produksi dilakukan berdasarkan pesanan pelanggan saja. Hal ini menyebabkan pendapatan setiap bulan tidak menentu bahkan cenderung tidak ada. Oleh karena itu, tim pengabdi sepakat untuk melakukan perbaikan dalam bidang pemasaran. Pemasaran dilakukan dengan memanfaatkan media sosial (facebook) dan toko online seperti shopee. Pemasaran dengan memanfaatkan teknologi digital ini membutuhkan pelatihan dari pakar yang kompeten, sehingga tim pengabdi melakukan pelatihan manajemen pemasaran dalam bentuk bimbingan teknologi (Bimtek) kilat selama 1 hari. Kegiatan dihadiri oleh 7 anggota IKM, tim pengabdi dan narasumber yang ahli dalam bidang pemasaran. Hasil yang dicapai dari pelatihan ini antara lain: adanya akun penjualan di facebook dan akun shopee dengan nama IKM Rumah Ikhtiar, anggota IKM sudah mahir melakukan pemasaran di facebook dan shopee serta penjualan selama 1 pekan setelah pemasaran menggunakan facebook dan shopee mengalami peningkatan dibandingkan sebelumnya. Jika sebelumnya penjualan VCO hanya 2 liter perminggu, setelah menggunakan strategi pemasaran dengan facebook dan shopee penjualan meningkat menjadi $6-10$ liter perminggu.
\end{abstract}

\section{Kata kunci: IKM, Minyak Murni, Arang, Etanol, Pemasaran}

\begin{abstract}
IKM Rumah Ikhtiar is an IKM that is engaged in coconut processing, especially the processing of VCO and its derivative products. The huge marketing potential of VCO, the demand for charcoal, and the use of ethanol as an ingredient for making hand sanitizers during the pandemic show that this IKM-processed product is quite important. However, currently production is carried out based on customer orders only. This causes the income every month to be erratic and even non-existent. Therefore, the service team agreed to make improvements in the marketing field. Marketing is done by utilizing social media (Facebook) and online stores such as Shopee. Marketing by utilizing digital technology requires training from competent experts, so the service team conducts marketing management training in the form of rapid technology
\end{abstract}


guidance (Bimtek) for 1 day. The activity was attended by 7 members of IKM, a team of service people and resource persons who are experts in the field of marketing. The results achieved from this training include: a sales account on Facebook and a shopee account under the name IKM Rumah Ikhtiar, IKM members are proficient in marketing on Facebook and Shopee and sales for 1 week after marketing using Facebook and Shopee has increased compared to before. Previously, VCO sales were only 2 liters per week, after using a marketing strategy with Facebook and Shopee, sales increased to 6-10 liters per week.

Keywords: SMI, Virgin Coconut Oil, Charcoal, Ethanol, Marketing

\section{PENDAHULUAN}

IKM Rumah Ikhtiar merupakan IKM yang bergerak dalam bidang pengolahan kelapa khususnya pengolahan VCO. IKM ini terletak di desa Posso, salah satu desa di Kecamatan Kwandang Kabupaten Gorontalo Utara. Kabupaten Gorontalo Utara merupakan salah satu kabupaten yang memiliki potensi penghasil kelapa yang cukup besar, yakni sekitar 15.000 buah/bulan. Potensi kelapa yang cukup besar ini memotivasi IKM untuk lebih mengoptimalkan olahan kelapa seperti VCO. Virgin Coconut Oil (VCO) merupakan minyak kelapa murni dengan kadar air dan kadar asam lemak bebas yang rendah, berbau harum, berwarna bening, dan daya simpan yang lama yakin berkisar antara 12 bulan atau lebih (Widiyanti, 2015). VCO merupakan salah satu produk yang dapat dikembangkan karena memiliki produk turunan yang dapat dimanfaatkan oleh masyarakat. VCO berfungsi untuk perawatan kulit, rambut, perawatan tubuh, dan dapat diminum untuk kesehatan tubuh (Ibrahim, dkk., 2019).

IKM Rumah Ikhtiar memiliki filosofi sebuah tempat usaha berkreasi dengan mandiri, berkumpul serta belajar menyatukan ide dan hasil olahan menjadi satu produk bersama. IKM Rumah Ikhtiar ini sebagian besar beranggotakan ibu-ibu rumah tangga (kalangan muda dan lansia) dan bapak-bapak pengepul (pengumpul) kelapa. Dengan adanya IKM ini diharapkan dapat memberdayakan masyarakat Desa khususnya ibu-ibu rumah tangga (istri petani) agar mempunyai pekerjaan sampingan yang dapat menjadi potensi pendapatan yang signifikan bagi kesejahteraan hidupnya.

Saat ini IKM mencoba untuk mengembangkan produk turunan VCO, yakni produk etanol dan arang. Menurut IKM biasanya pada saat pengolahan VCO, limbah seperti tempurung dan air kelapa cenderung tidak digunakan. Oleh karena itu, IKM berinsiatif untuk mengembangkan limbah ini menjadi produk yang bernilai jual. Tempurung diolah menjadi arang aktif (Jamilatun, dkk., 2015) sedangkan air kelapa diolah menjadi etanol (Turnip, dkk., 2016). Besarnya potensi pemasaran VCO, permintaan arang, dan penggunaan etanol sebagai bahan pembuatan handsanitizer di masa pandemi menunjukkan bahwa produk olahan IKM ini cukup penting dan dapat berkembang kedepannya.

\section{Permasalahan Mitra}

Berdasarkan hasil diskusi dengan ketua IKM Rumah ikhtiar, permasalahan yang dihadapi mitra yakni:

1. Minimnya pengetahuan anggota IKM Rumah Ikhtiar dalam hal manajemen usaha.

2. Minimnya produksi setiap bulannya disebabkan karena pemasaran yang dilakukan hanya sebatas door to door dan produksi dilakukan hanya jika ada pesanan dari pembeli.. 


\section{SOLUSI DAN TARGET LUARAN}

\section{Solusi Permasalahan}

Solusi permasalahan yang ditawarkan oleh tim pengabdi yakni:

1. Melakukan pelatihan manajemen usaha. Pelatihan manajemen untuk IKM ini sangatlah perlu dilakukan agar IKM ini memahami bagaimana strategi dalam membangun usaha supaya mendapatkan keuntungan yang mampu meningkatkan pendapatan masyarakat khususnya anggota IKM mitra sehingga kedepan produk yang mereka hasilkan dapat bersaing dengan produk sejenis bahkan dapat bermetamorfosis menjadi produk unggulan khas Gorontalo utara.

2. Melakukan pelatihan strategi pemasaran berbasis digital. Menurut Alford \& Oage (2015) menyatakan bahwa UKM tidak mengikuti perkembangan teknologi digital, khususnya karena kurangnya wawasan tentang pemasaran digital. Wardhana (2015) menyatakan bahwa strategi digital marketing berpengaruh hingga $78 \%$ terhadap keunggulan bersaing UMKM dalam memasarkan produknya

3. Pencarian mitra untuk membantu dalam penjualan produk. Mitra tersebut berupa toko-toko/supermarket dan oleh-oleh yang tersebar di seluruh Gorontalo

\section{Luaran dan Target Capaian}

Luaran yang diharapkan dari kegiatan ini adalah meningkatkan produksi IKM Rumah Ikhtiar setiap bulannya, meningkatkan penjualan dan pengetahuan pihak IKM mitra sehingga mampu mengelola usaha dengan professional.

\section{METODE PELAKSANAAN KEGIATAN}

Pelaksanaan kegiatan pelatihan ini didampingi oleh Tim Pengabdian yang terdiri dari dosen sebanyak 3 orang dan dibantu oleh 5 orang mahasiswa. Metode pelaksanaan dapat diuraikan sebagai berikut:

- Kegiatan pengabdian diawali koordinasi dengan pemerintah setempat tentang waktu yang tepat untuk dilaksanakan kegiatan PKM.

- Tim menyediakan narasumber yang ahli dalam bidang manajemen usaha dan pemasaran

- Penyuluhan dan pelatihan dilaksanakan dalam bentuk bimbingan teknologi (Bimtek) selama 1 hari

- Pelatihan diawali dengan materi manajemen usaha

- Pelatihan kedua yakni pelatihan strategi pemasaran berbasis digital dengan memanfaatkan media social dan akun jual beli online yakni shopee.

\section{HASIL DAN PEMBAHASAN}

Manajemen usaha dan pemasaran merupakan bagian penting yang dapat menunjang keberhasilan sebuah usaha. Pemahaman tentang manajemen usaha dapat membantu pelaku usaha untuk segala hal yang berkaitan dengan usahanya, mulai dari target dan tujuan yang akan dicapai, pengelolaan keuangan, aspek produksi dan lain-lain.

Pemasaran merupakan suatu usaha atau rencana-rencana strategis yang diarahkan oleh pelaku usaha untuk berinteraksi secara langsung kepada konsumen tentang produk yang mereka hasilkan untuk dipromosikan (Zainurossalamia, 2020). Strategi pemasaran adalah salah satu kegiatankegiatan pokok yang dilakukan oleh usaha untuk mempertahankan kelangsungan usaha, untuk berkembang, dan untuk mendapatkan laba (Vernia, dkk., 2019).

Saat ini teknik pemasaran sudah berkembang pesat. Penggunaan media sosial sebagai alat untuk memasarkan dinilai paling efektif dan efisien untuk menjual produk kepada konsumen. Dengan dasar ini maka tim pengabdi pun mengarahkan kepada IKM Mitra melakukan pemasaran melalui media sosial. 
Kegiatan pelatihan dihadiri oleh perwakilan dari pemerintah setempat dan pihak IKM Rumah Ikhtiar. Kegiatan diawali dengan pembukaan oleh pemerintah setempat dan dilanjutkan dengan materi. Materi dilakukan dengan metode ceramah dan diskusi. Materi pertama tentang manajemen usaha. Pemateri memberikan materi terkait cara pengelolaan usaha yang baik, cara pengelolaan keuangan dan penetapan harga produk. Pihak IKM sangat antusias mendengarkan materi yang diberikan. Hal ini dapat dilihat dari adanya pertanyaan-pertanyaan dari pihak IKM terkait dengan materi yang diberikan.

Kegiatan dilanjutkan dengan materi kedua yakni strategi pemasaran. Pelatihan strategi pemasaran yang diberikan adalah pemasaran yang berbasis digital dan memanfaatkan teknologi yang ada. Pengguna internet di Indonesia khususnya di Gorontalo cukup besar. Hampir semua kalangan masyarakat baik muda maupun tua menggunakan internet dan media sosial. Hal ini membuat pemasaran lebih efektif jika berbasis digital/online.

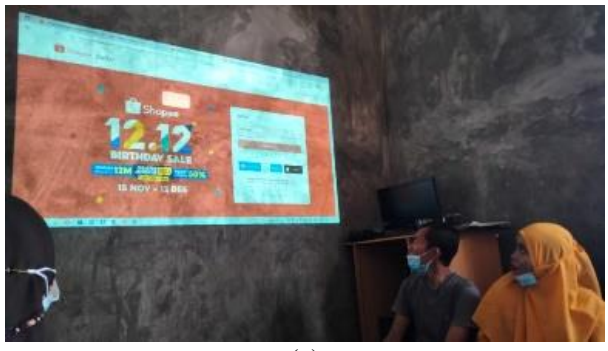

(a)

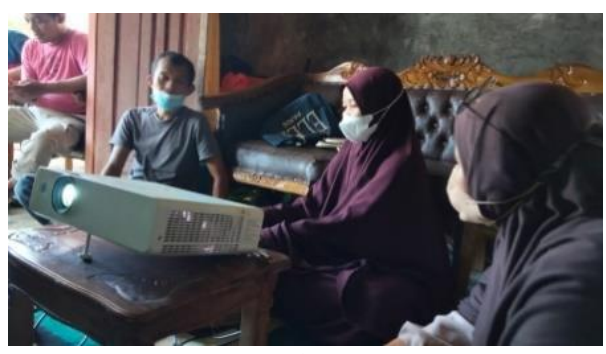

(b)

Gambar 1. Proses pelatihan pembuatan akun penjualan

Pada saat pemberian materi kedua, tim pengabdi dan mahasiswa melakukan pendampingan kepada pihak IKM. pada tahap ini pihak IKM dibimbing dalam membuat akun media sosial facebook untuk penjualan dan akun toko online shopee. Diharapkan nanti pihak IKM dapat membuat akun sendiri apabila ingin menambah akun penjualan online yang lainnya. Proses pelatihan pembuatan akun penjualan online disajikan pada Gambar 1, sedangkan tampilan akun yang telah dibuat disajikan pada Gambar 2.

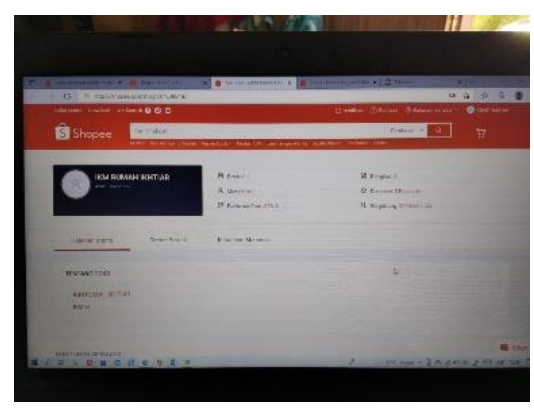

Gambar 2. Tampilan akun penjualan yang sudah dibuat

Materi strategi pemasaran yang diberikan cukup bagus dan membuat pihak IKM antusias dalam mencoba membuat akun penjualan online. Para anggota semangat dan merasa senang karena didampingi langsung oleh tim pengabdi. Kegiatan pemberian materi kedua berlangsung lancar dan menghasilkan akun penjualan yang siap digunakan.

Akun penjualan tersebut kemudian diujicobakan selama 1 pekan untuk melihat pengaruhnya terhadap penjualan IKM Rumah Ikhtiar. Produk yang dipasarkan di akun penjualan tersebut disajikan pada Gambar 3.

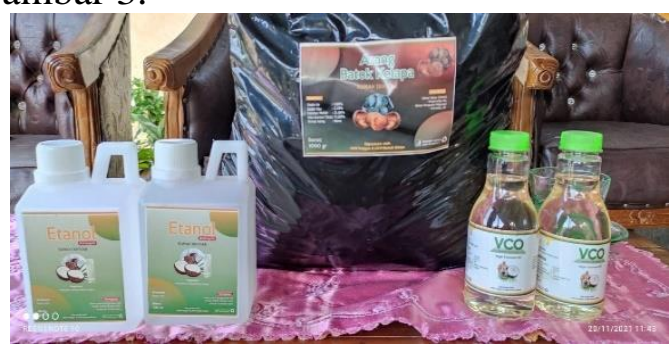

Gambar 3. Produk IKM Rumah Ikhtiar

Hasil yang diperoleh dari hasil pemasaran menggunakan akun penjualan online yakni terjadi peningkatan permintaan / pemesanan produk dari pelanggan. Jika sebelumnya penjualan VCO hanya 2 liter 
perminggu, setelah menggunakan strategi pemasaran dengan facebook dan shopee penjualan meningkat menjadi $6-10$ liter perminggu. Hal ini menunjukkan bahwa strategi pemasaran berbasis digital / online ternyata mampu meningkatkan penjualan dan pendapatan di IKM rumah ikhtiar.

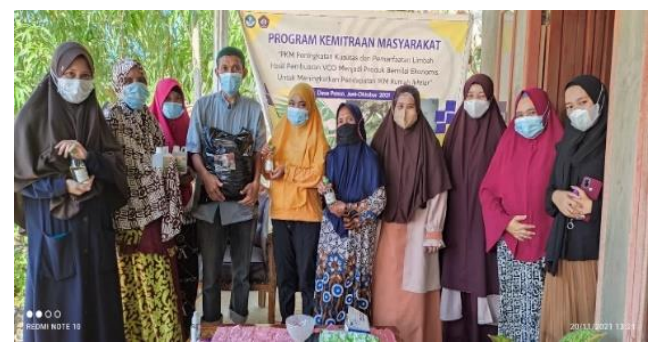

Gambar 4. Foto bersama IKM Rumah Ikhtiar

Dari kegiatan pengabdian ini, ada beberapa hal yang harus diperhatikan karena dapat menunjang kegiatan pemasaran, yakni:

a. Strategi pengembangan produk. Apabila IKM dihadapkan dengan produk yang semisal yang mungkin punya keunggulan. Maka tonjolkan keunggulan produk sendiri dan jangan takut berinovasi.

b. Belajar melakukan pembacaan pasar, sehingga IKM mampu menganalisis peluang adanya produk-produk baru yang dapat dikembangkan dari produk turunan VCO.

c. Melakukan respon pasar terkait produk yang kita produksi, bagaimana tanggapan dari konsumen dan apa saja yang menjadi masukan untuk perbaikan produk IKM rumah ikhtiar.

\section{KESIMPULAN DAN SARAN}

Program Kemitraan Masyarakat dengan tema pelatihan strategi pemasaran dalam pengembangan pemasaran dan kewirausahaan IKM Rumah Ikhtiar berjalan lancar. Pelatihan ini sangat bermanfaat bagi mitra karena adanya peningkatan pengetahuan tentang manajemen usaha dan keterampilan dalam memasarkan produk IKM rumah ikhtiar.
Penjualan dengan menggunakan media sosial dan akun penjualan online memberikan hasil yang signifikan. Jika sebelumnya penjualan VCO hanya 2 liter perminggu, setelah menggunakan strategi pemasaran dengan facebook dan shopee penjualan meningkat menjadi $6-10$ liter perminggu. Hal ini menunjukkan bahwa strategi pemasaran berbasis digital / online ternyata mampu meningkatkan penjualan dan pendapatan di IKM rumah ikhtiar.

Adapun Saran dalam kegiatan ini adalah perlu adanya pendampingan lebih lanjut supaya IKM rumah ikhtiar bisa lebih berkembang.

\section{DAFTAR PUSTAKA}

Alford, P \& Page, S.J (2015) Marketing technology for adoption by small business. The Service Industries Journal, 2015 Vol. 35, Nos. 11-12, 655-669

Ibrahim, P.S., Rosdiani, A., dan Ingka, R.A. 2019. Pelatihan Pembuatan VCO untuk Meningkatkan

Penghasilan Masyarakat. JPPM, Vol. 3, No. 2, Hal. 197-200.

Jamilatun, S., Martomo, S., Siti, S., Dwi, A.A.P., Riska, U.M.P. 2015. Pembuatan Arang Aktif dari Tempurung Kelapa dengan Aktivasi Sebelum dan Sesudah Pirolisis. Seminar Nasional Sains dan Teknologi, 17 November 2015.

Kotler, Philip. 1995. Marketing Jilid II. Jakarta: Erlangga.

Taiminen, H., \& Karjaluoto, H. (2015). The usage of digital marketing channels in SMEs. Journal of Small Business and Enterprise Development, 22 (4), 633-651

Turnip, T.T., Fajar, R., dan Evy, R. 2016. Potensi Air Kelapa dalam Proses Fermentasi Bioetanol dengan Penambahan NPK dan Tween $80^{\mathrm{TM}}$. Jom Faperta, Vol. 3, No. 2.

Vernia, D.M., Sigit, W., Dwi, N., Mu'thia, M., Leni, T. 2019. Sosialisasi dan 
Pembekalan Strategi Pemasaran Produk Olahan Pisang pada Siswa Pondok. Jurnal Pengabdian Untukmu Negeri, Vol. 3, No. 2.

Wardhana, A. (2015). Strategi Digital Marketing dan Implikasinya pada Keunggulan Bersaing UKM di Indonesia. Seminar Nasional Keuangan dan Bisnis IV UPI, 327-337.

Widiyanti, R. A. (2015). Pemanfaatan Kelapa Menjadi VCO (Virgin Coconut Oil) sebagai Antibiotik Kesehatan dalam Upaya Mendukung Visi Indonesia Sehat 2015. Prosiding Seminar Nasional Pendidikan Biologi 2015, yang diselenggarakan oleh Prodi Pendidikan Biologi FKIP Universitas Muhammadiyah Malang, 21 Maret 2015.

Zainurossalamia, S. 2020. Manajemen Pemasaran Teori dan Strategi. NTB:

Praya Lombok Tengah. 